\title{
Abirateron Asetatın Metastatik Prostat Kanserindeki Değişen Rolü
}

\author{
Öner Şanlı1, Ömer Barış Yücel ${ }^{1}$
}

${ }^{1}$ İstanbul Üniversitesi, Tıp Fakültesi, Üroloji Anabilim Dalı, İstanbul

\section{Giriş}

P rostat kanseri erkeklerde en sik görülen kanser olup kanser ölümlerinin ise; akciğer kanserinden sonra en sık ikinci nedenidir (1). Ülkemizde prevalansı gelişmiş batı toplumlarına göre daha düşük olmakla birlikte (ABD: 98.2/100000, Fransa: 98/100000, İngiltere: 73.2/100000, Türkiye: 39.2/100000), erkeklerde en sık görülen ikinci kanser türüdür. (http://kanser.gov.tr/haberler/1697-14-18). Prostat spesifik antijen (PSA)'in rutin olarak kullanılmasına karşın hastaların yaklaşık 1/3'lük kısmı metastatik hastalık ile başvurmakta ya da prostat kanserinin doğal seyri içerisinde metastatik hale gelmektedir. Metastatik prostat kanserinin temel tedavisi androjen çekilme tedavisi (ADT) ${ }^{*}$ olup; genel olarak LHRH agonistleri, LHRH antagonistleri veya orşiektomi ile yapılmaktadır. ${ }^{\dagger}$ Bu tedavi ile prostat kanseri ortanca 1 yıl süre ile kontrol altında tutulmakta, ancak sonrasında serum PSA seviyeleri testosteronun baskılanmasına rağmen ${ }^{\ddagger}$ yükselmeye başlamakta ve hasta metastatik kastrasyona dirençli prostat kanseri (mKDPK) evresine geçmektedir (2). ${ }^{\S}$ Hastalığın bu evresinde ortalama sağkalım, ikinci basamak tedavilerle birlikte kabaca $16-18$ aydır ${ }^{\mathbb{I I}}(3,4)$.

$\mathrm{Bu}$ dekatta, metastatik prostat kanserindeki en önemli gelişmelerden birisi; kemoterapinin hastalığın seyri sırasında değişen yeridir. Yakın zamana kadar prostat kanserinde etkinliği düşük olan dosetaksel kemoterapisi, hastalığın ancak en son evresinde; hasta ağrılı kemik lezyonları nedeniyle semptomatik hale geldiğinde verilmekteydi. Ancak CHAARTED çalışması, hastalığın bu evresinde ADT ve dosetakselin beraber kullanımının, yalnızca ADT kullanıma göre toplam sağkalımda belirgin bir avantaj sağladığını (57.6 aya karş1 44 ay, HR 0.61, \%95 CI, 0.47-0.80, p=0.0006) ortaya koydu (5). Bu "mihenk taşı" çalışmanın ortaya koyduğu önemli bir yenilik de, metastatik hastalıkta "düşük ve yüksek volümlü" hastalığın tanımlanmasıdır. Bu çalışmanın sonuçlarına göre; dosetakselin ADT'ye eklenmesinin meydana getirdiği sağkalım avantajı esas olarak yüksek volümlü hastalıkta ortaya çıkmaktadır. Yüksek volümlü hastalık ise; solid organ lezyonları (viseral hastalık) ve/veya en az bir tanesi omurgalar dışında olmak üzere 4 veya daha fazla kemik metastazını tanımlamaktadır. Bu çalışmanın verilerini yine randomize kontrollü çalışma (RKÇ) olarak gerçekleştirilen STAMPEDE'de konfirme etmiştir (ADT'ye karş1 ADT + dosetaksel, toplam sağkalımda 81 aya karşı 71.3 ay, HR 0.78, \%95 CI, 0.66-0.93; p=0.006) (6). Bu çalışmalar prostat kanserinde kemoterapinin yerini belirlemenin yanında, prostat kanserindeki metastatik lezyonların yeri ve sayısının bilinmesinin de önemini ortaya koymuş ve başta Galyum ${ }^{68}$ PSMA PET-CT olmak üzere, prostat kanserine yönelik pek çok görüntüleme yöntemini gündeme getirmiştir (7). Tüm bu gelişmelere karşın, ileri hasta yaşı ve eşlik eden komorbiditeler, erken kemoterapinin önündeki en büyük engeller olarak varlığını sürdürmektedir.

Prostat kanseri temelde hormona bağımlı bir tümör olup, tümörün büyümesini stimule eden testosteron üretimi, ADT ile bloke edilir. Buna karşın, tümör kendisi için gerekli stimulasyonu; adrenal bezlerden salgılanan androjenlerle, tümör içi üretimle veya aberan androjen sinyal yolağ sağlamaktadır (8). Yine bu dekatta meydana gelen diğer bir gelişme de; adrenal bezden salgılanan androjenleri bloke eden ilaçların klinik kullanıma girmesidir. Bunlardan birisi olan abirateron asetat (AA) bir pregnenolon analoğudur ve aktif metaboliti "abirateron" sitokrom P450c17 (CYP17)'yi geri dönüşümsüz olarak engeller. Böylece androjenlerin üretiminden sorumlu olan biri dizi enzimi inhibe ederek ekstragonadal ve intratümöral androjen sentezini bloke eder (9).

Abirateron asetatın prostat kanserindeki klasik kullanım yeri, kastrasyona dirençli prostat kanserinde kemoterapi sonrasıdır (3). Bu konuyla ilgili temel çalışma 2012'de yayınlanan COU-AA-301 çalışmasıdır (3). Daha önce dosetaksel ile progresyon gösteren hastalarda, AA (1 gr/gün) ile birlikte prednisolon (5 mg/gün), plasebo ile karşılaştırılmıştır. Toplam 1195 hastanın, 2:1 oranında randomize edildiği çalışmanın ara değerlendirme sonuçlarına göre; toplam sağkalım AA grubunda 15.8 ay, plasebo grubunda 11.2 ay olarak saptanmiştır (HR 0.74, \%95 CI, 0.64-0.86; p=0.0001). Bu değerlendirme ile AA, FDA onayı almış ve ülkemizde de halen Sağlık Bakanlı̆̆ı'nın bu endikasyon onayı ile tedavide yoğun olarak kullanılmaktadır.

Abirateron asetatın yukarıda değinilen temel kullanımına

* $\quad \mathrm{ADT}=$ androgen deprivation theraphy. Bu yazida kisaltma olarak bu "evrensel" kisaltma kullanilmistir.

† Antiandrojenlerin GnRH analoglarına eklenmesi (maksimal androjen blokajı) 5-yıllık sağkalımı yalnizca \%1.8 (\%25.4'e karşı \%23.6) oranında artırdığından, günümüzde bu şekildeki kombinasyon tedavisi giderek azalan oranda kullanılmaktadır (Prostate Cancer Trialists' Collaberative Group, The Lancet 2000; 355, 1491-1498).

$\ddagger \quad$ Bu değer klasik olarak $<50 \mathrm{ng} / \mathrm{ml}$ olarak kabul edilse de; son dönemde $20 \mathrm{ng} / \mathrm{ml}$ olarak güncellenmektedir.

$\S$ STAMPEDE çalışmasının kontrol grubunda tedavi başarısızlığına kadar geçen süre 11 ay olarak rapor edilmiştir.

II Bu veriler COU-AA-301 (abirateron asetat) ve AFFIRM (enzalutamid) çalışmalarının tedavi gruplarından güven aralıkları göz önünde bulundurularak yuvarlanmıştır. Gerçek değerler her iki çalışma için sırasıyla 15.8 (\%95 CI 14.8-17.0) ve 18.4 (\%95 CI 17.3-ulasilamamis) olarak verilmektedir. 


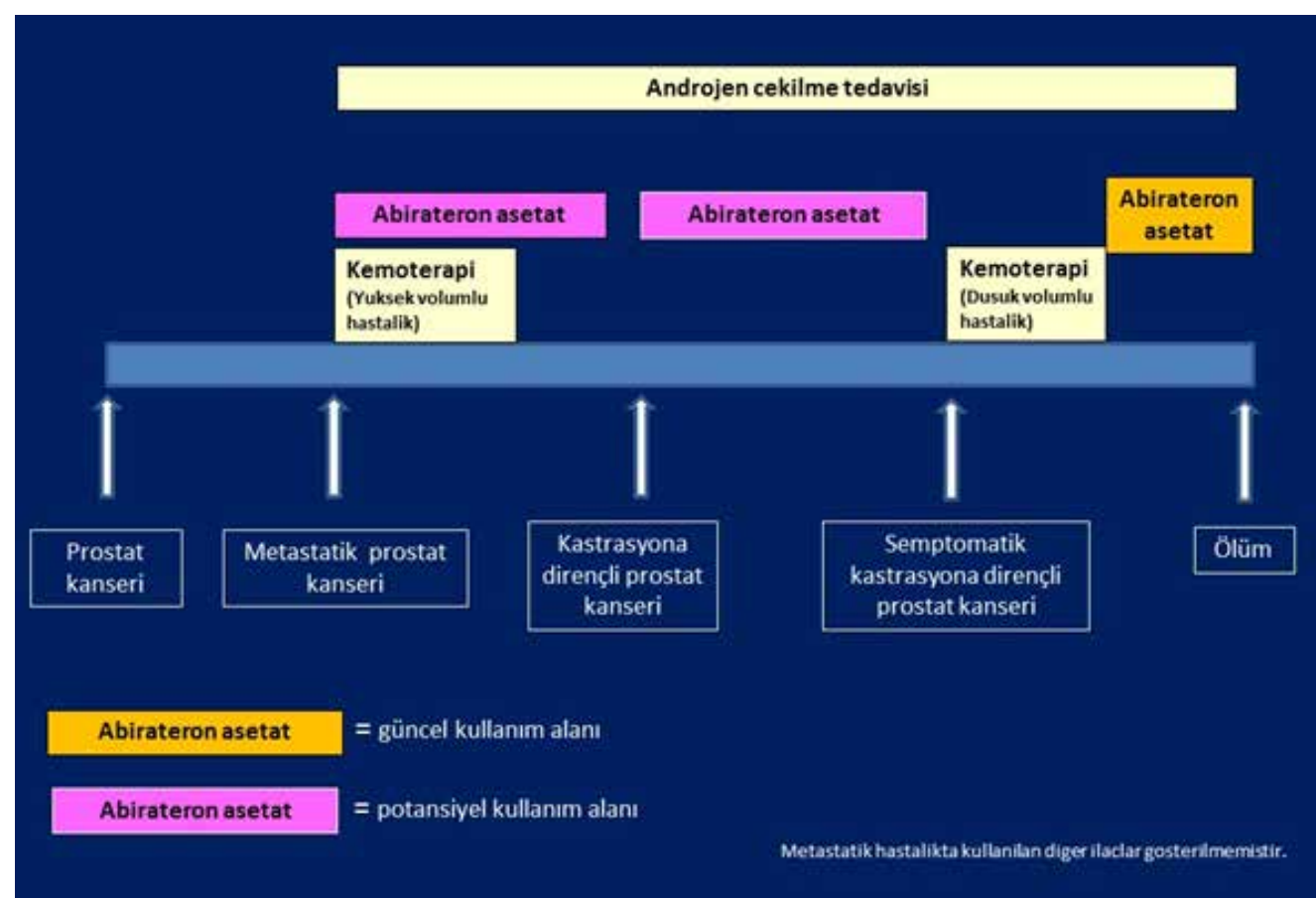

Şekil 1: Metastatik prostat kanserinde abirateron asetatın değişen rolünün şematik gösterimi

ilave olarak son dönemde yayınlanan çalışmalar, metastatik hastalığın çok daha erken evrelerinde de kullanılabileceğini ortaya koymuştur (Şekil 1). Bunların ilki; mKDPK'inde dosetaksel öncesi kullanımıdır. COU-AA-302 çalışması, bu evredeki hastalarda yine önceki çalışma ile benzer şekilde kanıta dayalı tıp prensipleriyle yapılmıştır (10). En son 2015 yılında yapılan değerlendirme sonuçlarına göre; 49.2 aylık takip sonucunda toplam sağkalım, AA grubunda 34.7 ay, plasebo grubunda 30.3 ay olarak rapor edilmiştir (HR:0.81, \%95 CI, 0.70-0.93; $\mathrm{p}=0.0033$ ). Bu çalışmanın ara değerlendirmesine dayanarak 2012 yılında FDA, AA'ın dosetaksel öncesi kullanımını onaylamıştır (10).

Son dönemde meydana gelen belki de en çarpıcı gelişme, AA'ın, yeni tanı almış, henüz androjen çekilme tedavisi başlanmamış hastalarda kullanımıdır. Bu konu ile ilgili plasebo kontrollü, çift kör, randomize kontrollü çalışmalar Temmuz 2017'de yayımlanmıştır. Toplam 1199 hastanın, 1:1 eşleştirme ile dahil edildiği ilk çalışmada (LATTITUDE), bir gruba klasik ADT ile birlikte AA (1000 mg/gün + 5 mg prednisolon); diğer gruba ise klasik ADT ile birlikte plasebo uygulanmıştır (11). Çalışmanın birincil sonlanım parametreleri; ortalama sağkalım ve radyolojik ${ }^{* *}$ progresyonsuz sağkalım olarak belirlenmiştir. Ortanca 30.4 aylık takip süresi sonunda yapılan ara değerlendirmede ölüm oranının AA grubunda, plasebo grubuna göre \%38 oranında az olduğu (HR: 0.62; \%95 CI 0.51-0.76; p< 0.001) görülmüştür. Üç yıllık ortalama sağkalım plasebo grubunda \%49 olarak saptanırken, AA grubunda \%66 olarak tespit edilmiştir. Radyolojik progresyonsuz sağkalım ise plasebo grubunda 14.8 ay, AA grubunda 33 ay (HR: 0.47, \%95 CI 0.39-0.55; $\mathrm{p}<0.001$ ) olarak rapor edilmiştir. Diğer sonlanım parametreleri olan ağrı, progresyona kadar geçen süre $(\mathrm{p}<0.001)^{\dagger+}$, bir sonraki tedaviye kadar geçen süre $(p<0.001)$, kemoterapiye kadar geçen süre $(p<0.001)$, PSA progresyonuna kadar geçen süre $(p<0.001)$ ve semptomatik kemik olaylarına kadar geçen süre $(p=0.009)$ AA grubunda, plasebo grubuna göre çok daha uzun bulunmuştur. Yan etkiler açısından bakıldığında, her iki grupta ciddi yan etki yaşayan hastaların sayısı benzer olarak saptanmış ve tedaviyi bırakma oranları her iki grup için sırasıyla \%10 ve \%12 olarak rapor edilmiştir.

Diğer çalışma ise çok kollu, çok evreli çalışma tasarımı (multi-arm, multi-stage [MAMS]) olan STAMPEDE'nin bir koludur (Şekil 2) ve diğerine göre çok daha heterojen bir hasta popülasyonunu içermektedir (12). Toplam 1917 hastanın randomize edildiği çalışmada, hastaların \%27'sinde; yüksek riskli lenf nodu (LN) negatif ve nonmetastatik

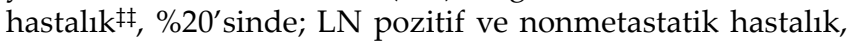
$\% 50$ 'sinde; metastatik hastalık, \%3'ünde daha önce tedavi almamış nonmetastatik hastalık ve \%1'inde daha önce hormon dışı tedaviler almış metastatik hastalık saptanmıştır. Ortanca 40 aylık takip sonucunda; tüm gruplar göz önüne alındığında, ortalama sağkalım, ADT+AA grubunda istatistiksel olarak daha iyi (HR:0.63, \%95 CI 0.53-0.76) rapor edilmiştir ki; bu durum \%37 oranında rölatif risk azalmasına işaret etmektedir. Üç yıllık sağkalım, ADT+AA ve AA grubunda sırasıyla \%83 ve \%76 olarak bildirilmiştir. Ayrıca rölatif risk azalması, metastatik ve nonmetastatik grupta \%39 ve $\% 25$ olarak tespit edilmiştir. Diğer taraftan çalışmanın ikincil sonlanım kriterlerinden birisi olan progresyonsuz sağkalım, ADT+AA grubunda \%80, yalnız ADT grubunda ise $\% 62$

** Orjinal metinde radyografik olarak gecmektedir.

t+ Ağrı progresyonu, Kısa Ağrı Değerlendirme Formu (Brief Inventory Short Form) ile değerlendirilmiş ve 4 hafta ara ile yapılan değerlendirmede, bazale göre $\% 30$ daha fazla ağrının tespit edilmesi pozitif olarak kabul edilmiştir.

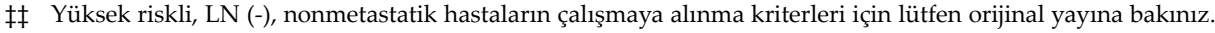




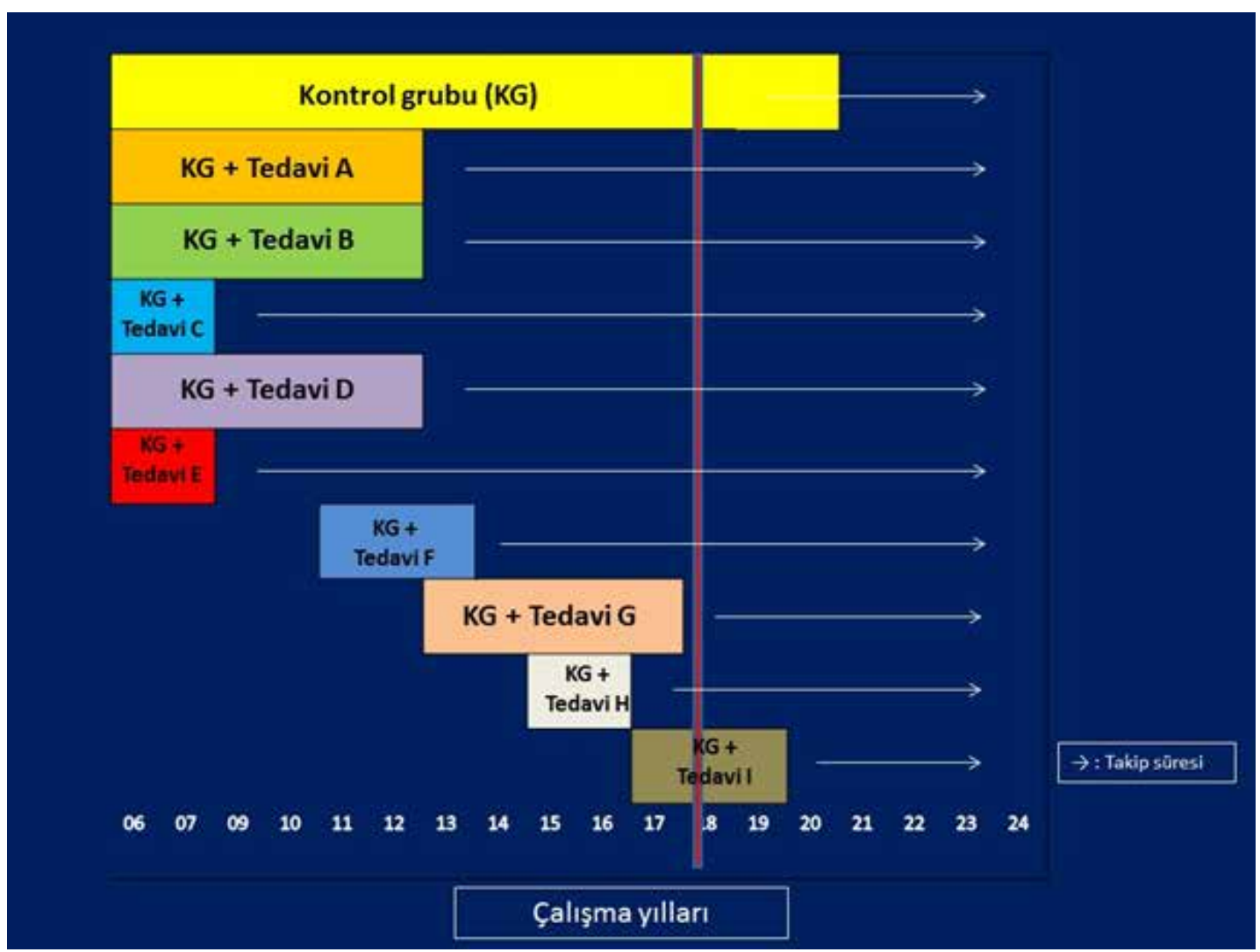

Şekil 2: Tıp literatüründe giderek daha fazla yer almaya başlayan ve temel hedefi çalışma maliyetlerini düşürmek olan çok kollu, çok evreli çalışma tasarımı (multi-arm, multi-stage [MAMS], ilgli referansdan uyarlanmıştır) (14). STAMPEDE'nin ilk örneği olduğu bu çalışma türünde, pek çok yeni tedavi stratejisi, tek bir standart kontrol grubu ile karşılaştırılmaktadır. Kabaca STAMPEDE çalışmasında 5 yeni tedavi stratejisi ortak bir kontrol grubu ile karşılaştırılmış ve ara değerlendirmelerde, kontrol grubuna göre sağkalım avantajı yaratan tedavi modaliteleri, ileri fazlara geçebilmişlerdir (15). Çalışmanın daha başında ara değerlendirmeler planlanmış, çalışmanın gücü yüksek tutulmuş ve hipotezi reddetmek için gerekli olan " $p$ " değeri de önceden belirlenmiştir. Böylece planlanan 4 ara değerlendirmenin ikisi ile o tedavi modalitesinin ileri fazlara geçip geçmemesine karar verilir. Bu sırada çalışmaya yeni tedavi kolları eklenebilir. STAMPEDE çalışmasında zaman içerisinde etkinliği gösterilemeyen 2 tedavi kolu çalışma dışı bırakılmış; buna karşın 4 yeni tedavi kolu ilave edilmiştir. Böylece yalnizca çalışma maliyetleri düşürülmekle kalmayıp, ayni zamanda, yeni tedavilerin klinik değerlendirilmesi hızlandırılmıştır. STAMPEDE çalışmasının çıkış noktası, metastatik hastalıkta dosetakselin yerinin yeniden belirlenmesi olmasına karşın, zaman içerisinde yeni tedavi kollarından birisini AA oluşturmuştur. Hali hazırda da STAMPEDE bazı yeni tedavi alternatiflerini denemek için yoluna devam etmektedir. Sonuçta her yeni tedavi stratejisinin karşılaştıııldığı aynı kontrol grubudur. Bu hali ile çalışmayı pek çok değişik misyonun ve deneyin gerçekleştirildiği Uluslararası Uzay İstasyonuna benzetmek yanlış olmaz.

olarak (HR: 0.40\$§; \%95 CI, 0.34-0.47; p,0.001) saptanmıştır. Çalışmanın ilk yılında herhangi bir progresyonun yaşanmadığı 1476 hasta, güvenirlilik açısından değerlendirildiğinde, grade 3 veya daha fazla yan etki görülme oranı, ADT+AA ve yalnız ADT gruplarında sirasılla \%15 ve \%11 olarak tespit edilmiştir.

Yine bu iki çalışmadaki verileri kullanarak yapılan bir metaanalizde, hormona duyarlı metastatik evrede bulunan 2201 hasta değerlendirilmiş ve sonuçta ADT+AA grubunda, yalnız AA grubuna göre ölüm riskinde \%38 azalma $(\mathrm{HR}=0.62$, \%95 CI 0.53-0.71) saptanmıştır.(13) Bu durum toplam sağka- lımda \%14'lük bir avantaj (\%69'a karşı \%55) ${ }^{\text {III }}$ sağlamaktadır. Progresyonsuz sağkalım açısından ADT+AA tedavisi alan hastalarda, yalnız ADT alan hastalara göre \%55 oranında (HR: $0.45, \% 95$ CI $0.40=0.51, p=0.66 \times 10^{-36}$ ) bir risk azalmas1 söz konusudur. Bunun yanında hastalar Gleason skoru $(p=0.42)$; performans durumu $(p=0.31)$ ve $L N$ durumuna $(p=0.77)$ göre değerlendirildiğinde tedavi etkinliği açısından herhangi bir varyasyon saptanmamıştır. Yan etki durumuna baktığımızda ise; genel olarak kas-iskelet, gastrointestinal ve solunum sistemlerinde Grade 3 ve 4 yan etkiler açısından fark bulunmamasına karşın; akut kardiyak ve vasküler

$\S \S \mathrm{Bu} H R$ değeri klinik veya radyolojik progresyon veya prostat kanserinden ölüm için geçerlidir.

III Burada not edilmesi gereken nokta, STAMPEDE çalışmasında elde edilen HR değerinin, LATTITUDE çalışmasındaki ADT+AA grubuna uygulanmış olmasıdır. Bunun nedeni ise LATTITUDE çalışmasında HR hesaplanacak kadar ölümün meydana gelmemiş olmasıdır. 
olaylar ile hepatik toksisitede, kombinasyon grubu aleyhine istatistiksel anlamlı sonuçlar $(\mathrm{p}<0.001)$ bulunmuştur.

Sonuç olarak; metastatik prostat kanserinin tedavisi günümüzde hızla değişmektedir. Yukarıda bahsedilen kanıta dayalı çalışmaların ışığında, ADT'ye AA'ın eklenmesi, klasik ADT tedavisine göre çok daha etkili bir alternatifidir. Bu şekliyle de; prostat kanserinde $\mathrm{AA}^{\prime}$ ın yeri metastatik hastalığın sonlarından başlarına doğru yer değiştirmektedir (Şekil 1).

\section{Kaynaklar}

1. Siegel R, Ma J, Zou Z, et al. Cancer statistics, 2014. CA: a cancer journal for clinicians. CA Cancer J Clin;64;9-29, 2014.

2. James ND, Spears MR, Clarke NW, et al. Survival with Newly Diagnosed Metastatic Prostate Cancer in the "Docetaxel Era": Data from 917 Patients in the Control Arm of the STAMPEDE Trial (MRC PR08, CRUK/06/019). Eur Urol;67:1028-1038, 2015.

3. Fizazi K, Scher HI, Molina A, et al. Abirateron asetat for treatment of metastatic castration-resistant prostate cancer: final overall survival analysis of the COU-AA-301 randomised, double-blind, placebo-controlled phase 3 study. Lancet Oncol;13:983-992, 2012.

4. Scher HI, Fizazi K, Saad F, et al. Increased survival with enzalutamide in prostate cancer after chemotherapy. N Engl J Med;367:1187-1197, 2012.

5. Sweeney CJ, Chen YH, Carducci M, et al. Chemohormonal Therapy in Metastatic Hormone-Sensitive Prostate Cancer. N Engl J Med;373:737-746, 2015.

6. James ND, Sydes MR, Clarke NW, et al. Addition of docetaxel, zoledronic acid, or both to first-line long-term hormone therapy in prostate cancer (STAMPEDE): survival results from an adaptive, multiarm, multistage, platform randomised controlled trial. Lancet;387:1163-1177, 2016.

7. Sanli Y, Kuyumcu S, Sanli O, et al. Relationships between serum PSA levels, Gleason scores and results of 68Ga-PSMAPET/CT in patients with recurrent prostate cancer. Ann Nucl Med;3:709-717, 2017.
8. Yamaoka M, Hara T, Kusaka M. Overcoming persistent dependency on androgen signaling after progression to castration-resistant prostate cancer. Clin Cancer Res Sep;16:4319-24, 2010.

9. Del Re M, Fogli S, Derosa L, et al. The role of drug-drug interactions in prostate cancer treatment: Focus on abirateron asetat/prednisone and enzalutamide. Cancer Treat Rev;55:71-82, 2017.

10. Ryan CJ, Smith MR, Fizazi K, et al. Abirateron asetat plus prednisone versus placebo plus prednisone in chemotherapy-naive men with metastatic castration-resistant prostate cancer (COU-AA-302): final overall survival analysis of a randomised, double-blind, placebo-controlled phase 3 study. Lancet Oncol;16:152-60, 2015.

11. Fizazi K, Tran N, Fein L, et al. Abirateron plus Prednisone in Metastatic, Castration-Sensitive Prostate Cancer. N Eng J Med;377:352-360, 2017.

12. James ND, de Bono JS, Spears MR, et al. Abirateron for Prostate Cancer Not Previously Treated with Hormone Therapy. N Eng J Med;377:338-51, 2017.

13. Rydzewska LHM, Burdett S, Vale CL, et al. Adding abirateron to androgen deprivation therapy in men with metastatic hormone-sensitive prostate cancer: A systematic review and meta-analysis. Eur J Cancer;84:88-101, 2017.

14. Wason J, Magirr D, Law M, et al. Some recommendations for multi-arm multi-stage trials. Stat Methods Med Res;25:716-27, 2016.

15. Lin J, Bunn V. Comparison of multi-arm multi-stage design and adaptive randomization in platform clinical trials. Contemp Clin Trials;54:48-59, 2017.

Yazışma Adresi:

Öner Şanli,

İstanbul Üniversitesi, Tıp Fakültesi, Üroloji Anabilim Dalı, İstanbul Tel: +905353001236

e-mail: onersanli@hotmail.com 